\title{
PELATIHAN PENULISAN SURAT DINAS PADA PERANGKAT KANTOR DESA JATISELA KECAMATAN GUNUNG SARI LOMBOK BARAT
}

\author{
Baiq Yuliatin Ihsani ${ }^{1}$, Titin Untari ${ }^{2}$, Linda Ayu Darmutika ${ }^{3}$ \\ Dosen Proram Studi Pendidikan Bahasa Indonesia Universitas Muhamadiyah Mataram \\ Email: baiqyulia120789@gmail.com
}

\begin{abstract}
ABSTRAK
Abstrak: Tujuan pelatihan penulisan surat dinas pada perangkat kantor desa Jatisela adalah untuk meningkatkan pemahaman perangkat desa tentang penulisan surat resmi yang baik dan benar. Kegiatan program pengabdian pada masyaakat ini berlangsung selama tiga hari, yaitu pada tanggal 22, 23, 24 November 2017 yang bertempat di aula Kantor Desa Jatisela. Jumlah perangkat/staf desa yang mengikuti pelatihan penulisan surat dinas ini berjumlah 8 orang. Berdasarkan tabel di atas, nilai ejaan peserta kegiatan sudah sangat baik, artinya bahwa ada peningkatan dalam memahami Ejaan Bahasa Indonesia. Pada hari ini juga, peserta kegiatan dan tim pelaksana mengadakan refleksi dan evaluasi mengenai materi yang sudah disampaikan. Dengan demikian, peserta kegiatan dapat menyusun surat dinas dengan baik dan benar sesuai Pedoman Umum Ejaan Bahasa Indonesia.

Kata Kunci : Pelatihan, Surat Dinas, Perangkat Desa

Abstract: The purpose of training on writing the official letter on the Jatisela village office equipment is to improve the understanding of village apparatus about writing good and correct official letter. The program of community service activity lasted for three days, ie on 22, 23, 24 November 2017 which was held in the hall of Jatisela Village Office. The number of village staff / staff attending this letter writing training is 8 people. Based on the above table, the spelling value of the participants is very good, meaning that there is an improvement in understanding the Indonesian Spelling. On this day also, the participants of the activity and the implementing team held a reflection and evaluation of the material that has been delivered. Thus, the participants of the activity can prepare the letter of service well and correctly in accordance with the General Spellings Guidelines of Indonesia.
\end{abstract}

Keywords: Training, Letter of Service, Village Device

Riwayat Artikel: Diterima: 12 Desember 2017, Disetujui: 10 Januari 2018 


\section{A. PENDAHULUAN}

\section{Analisis Situasi}

Bahasa memiliki peranan yang sangat penting dalam kehidupan manusia. Bahasa merupakan alat komunikasi yang digunakan untuk menyampaikan ide, gagasan, perasaan, dan ekspresi mengenai sesuatu. Setiap melakukan aktivitas, manusia selalu menggunakan bahasa. Dalam berbagai macam situasi, bahasa dapat dimanfaatkan untuk menyampaikan gagasan pembicara kepada pendengar atau penulis kepada pembaca. Berkaitan dengan hal tersebut, ragam bahasa menurut sarananya dibagi menjadi dua, yaitu ragam lisan dan tulisan.

Dalam penggunaannya, ragam lisan lebih mudah digunakan daripada ragam tulisan. Ragam lisan digunakan ketika pembicara berhadapan langsung dengan pendengar. Oleh karena itu, unsur-unsur seperti gerak isyarat, pandangan, atau anggukan sebagai tanda penegasan, tinggi rendahnya aksen pengucapan dapat terlihat langsung dari pembicara. Sementara itu, dalam ragam tulisan pihak yang diajak berbahasa tidak berhadapan langsung. Oleh karena itu, agar pembaca memahami maksud yang diungkapkan penulis, bahasa yang digunakan harus lebih terang dan jelas serta eksplisit karena bahasa tulis tidak dapat disertai gerak isyarat, aksen, pandangan atau anggukan sebagaimana yang digunakan dalam ragam lisan. Dengan kata lain, ragam lisan lebih mudah dipahami daripada ragam tulisan.

Bahasa tulis membutuhkan kesempurnaan lebih daripada bahasa lisan. Bahasa tulis akan sulit dipahami jika penggunaanya tidak tepat atau tidak sesuai dengan kaidah kebahasaan. Oleh karena itu, penguasaan bahasa tulis mutlak diperlukan oleh seorang penulis agar pesan yang disampaikan dapat dipahami dengan baik oleh pembaca. Lebih lanjut dapat dijelaskan bahwa pemahaman tata bahasa perlu diperhatikan dalam menulis yang bersifat ilmiah maupun nonilmiah. Menulis harus menggunakan atauran-atauran baku yang terdapat dalam bahasa Indonesia.

Namun, pada kenyataannya banyak pemakai bahasa tulis yang kurang memperhatikan kaidah kebahasaan seperti yang terdapat dalam penggunaan bahasa tulis surat dinas di Kantor Desa Jatisela. Berdasarkan pantauan penulis, ditemukan berbagai bentuk kesalahan dalam penulisan surat dinas tersebut, seperti penggunaan huruf kapital, penggunaan tanda baca, penggunaan huruf miring, pemilihan kata, dan penggunaan kata tugas. Kesalahan-kesalahan dalam penulisan surat dinas tersebut tentu akan mengganggu kaidah kebahasaan. Surat dinas hendaknya menggunakan bahasa baku dan mengikuti kaidah-kaidah kebahasaan seperti yang telah diatur dalam Pedoman Umum Ejaan Bahasa Indonesia (PUEBI).

Perangkat desa yang ada di Kantor Desa Jatisela mengaku bahwa mereka membuat surat dinas tersebut berdasarkan pengetahuan yang diperoleh dari bangku sekolah. Mereka belum pernah mendapatkan pelatihan secara khusus tentang penulisan surat dinas yang sesuai dengan PUEBI. Sementara itu, surat dinas bersifat resmi dan megandung aturan serta etika yang sangat perlu diperhatikan dalam penulisannya agar pesan yang ingin disampaikan dapat dipahami dengan baik oleh yang menerimanya. Atas dasar permasalahan itulah kami bermaksud ingin mengadakan pelatihan penulisan surat dinas pada perangkat kantor Desa Jatisela dengan tujuan untuk meningkatkan pemahaman perangkat desa tentang penulisan surat resmi yang baik dan benar.

\section{Permasalahan Mitra}

Berdasarkan uraian di atas dapat dirumuskan permasalahan sebagai berikut.

a. Bagaimanakah proses penulisan surat dinas pada perangkat kantor Desa 
Jatisela Kecamatan Gunung Sari Lombok Barat?

b. Bagaimanakah kemampuan penulisan surat dinas pada perangkat kantor Desa Jatisela Kecamatan Gunung Sari Lombok Barat?

\section{B. METODE PELAKSANAAN KEGIATAN}

\section{Langkah-Langkah Kegiatan}

Kegiatan Program Pengabdian Pada Masyarakat dilaksanakan selama tiga hari, yaitu hari I penyampaian teori, hari II dan III digunakan untuk latihan penulisan surat dinas yang baik dan benar sesuai dengan Pedoman Umum Ejaan Bahasa Indonesia. Adapun langkah-langkah pelaksanaan Kegiatan Program Pengabdian Kepada Masyarakat adalah sebagai berikut.

a. Hari pertama, tim pelaksana kegiatan menyampaikan teori mengenai pengertian dan struktur surat dinas serta Pedoman Umum Ejaan Bahasa Indonesia yang diselingi dengan tanya jawab dan diskusi.

b. Hari kedua, peserta kegiatan latihan untuk menyusun surat dinas sesuai dengan Pedoman Umum Ejaan Bahasa Indonesia yang dipandu oleh Tim pelaksana kegiatan. Setelah dipandu, peserta kegiatan menyusun surat dinas secara mandiri untuk mengetahui pemahaman peserta kegiatan mengenai teori yang sudah disampaikan.

c. Hari ketiga, tim pelaksana kegiatan menyampaikan hasil kerja peserta kegiatan dan menyampaikan bentuk-bentuk kesalahan yang terjadi dalam penyusunan surat dinas. Kemudian, tim pelaksana kegiatan menyampaikan kembali teori yang lebih mendalam mengenai penulisan surat dinas yang baik dan benar sesuai dengan Pedoman Umum Ejaan Bahasa Indonesia. Selain itu, pada tahap ini, tim pelaksana kegiatan dan peserta kegiatan mengadakan refleksi dan evaluasi mengenai teori kegiatan yang sudah dilaksanakan.

\section{Khalayak Sasaran}

Kegiatan pengabdian pada masyarakat ini ditujukan pada perangkat/staf desa Kantor Jatisela, Kecamatan Gunung Sari Lombok Barat. Jumlah perangkat/staf desa yang mengikuti pelatihan penulisan surat dinas ini berjumlah 8 orang. Adapun peserta kegiatan dapat dilihat dalam tabel di bawah ini.

TABEL 1

KHALAYAK SASARAN

\begin{tabular}{|l|l|c|l|}
\hline No & \multicolumn{1}{|c|}{ Nama } & $\begin{array}{c}\text { Pendidikan } \\
\text { Terakhir }\end{array}$ & \multicolumn{1}{|c|}{ Jabatan } \\
\hline 1. & Zahar Mahmud & SMA & Kepala Desa \\
\hline 2. & Masypuk Alhamdani, S.E & S1 Ekonomi & Sekretaris Desa \\
\hline 3. & Faesal, A.Ma. & D2 & Kasi Pemerintahan \\
\hline 4. & Rohaniyah & SMA & Rohaniyah \\
\hline 5. & Rosyhandi Permana, A.Md. & D3 & Kasi Pelayanan \\
\hline 6. & Jaka Samudra & SMA & Kaur TU dan Umum \\
\hline 7. & Abdurrahman & SMA & Kaur Perencanaan \\
\hline 8. & Munahar & SMP & Kaur Keuangan \\
\hline
\end{tabular}

Kegiatan pelatihan ini dilaksanakan dengan harapan agar ketidakpahaman perangkat/staf desa dalam menulis surat dinas yang baik dan benar sesuai dengan Pedoman Umum Ejaan Bahasa Indonesia yang selama ini dialami oleh perangkat/staf desa Kantor Jatisela dapat diatasi. Setidak-tidaknya perangkat desa dapat terbantu untuk meningkatkan profesionalisme diri sebagai pegawai pemerintahan. 


\section{HASIL DAN PEMBAHASAN}

\section{Proses Pelaksanaan Kegiatan}

Kegiatan program pengabdian pada masyaakat ini berlangsung selama tiga hari, yaitu pada tanggal 22, 23, 24 November 2017 yang bertempat di aula Kantor Desa Jatisela. Kegiatan ini dimulai pada pukul 14.00 - 15.30 WITA dengan alasan supaya tidak mengganggu pelayanan staf desa kepada masyarakat.

a. Hari pertama, tim pengabdian pada masyarakat menyampaikan teori tentang pengertian dan struktur surat dinas. Selain itu, tim secara bergantian menyampaikan teori tentang Pedoman Umum Ejaan Bahasa Indonesia. Adapun perangkat/staf desa yang hadir dalam pembekalan teori ini dapat dilihat dalam tabel di bawah ini.

TABEL 2

PESERTA KEGIATAN

\begin{tabular}{|l|c|l|}
\hline \multicolumn{1}{|c|}{ Nama } & Pendidikan Terakhir & \multicolumn{1}{c|}{ Jabatan } \\
\hline Zahar Mahmud & SMA & Kepala Desa \\
\hline Masypuk Alhamdani, S.E & S1 Ekonomi & Sekretaris Desa \\
\hline Faesal, A.Ma. & D2 & Kasi Pemerintahan \\
\hline Rohaniyah & SMA & Rohaniyah \\
\hline Rosyhandi Permana, A.Md. & D3 & Kasi Pelayanan \\
\hline Jaka Samudra & SMA & $\begin{array}{l}\text { Kaur TU dan } \\
\text { Umum }\end{array}$ \\
\hline Abdurrahman & SMA & Kaur Perencanaan \\
\hline Munahar & SMP & Kaur Keuangan \\
\hline
\end{tabular}

Dalam kegiatan ini, tim pengabdian pada masyarakat dan peserta kegiatan mengadakan tanya jawab supaya peserta kegiatan mampu memahami dengan jelas mengenai teori yang disampaikan. Peserta kegiatan sangat antusias mengikuti pembekalan teori ini karena staf desa mengaku bahwa materi ini sangat penting untuk pebaikan penyusunan surat dinas yang lebih baik dan sesuai dengan Pedoman Umum Ejaan Bahasa Indonesia.

b. Hari kedua, peserta kegiatan mengadakan latihan penyusunan surat dinas yang sesuai dengan Pedoman Umum Ejaan Bahasa Indonesia. Pada tahap ini, perangkat/staf desa dipandu oleh tim pelaksana kegiatan dalam menyusun surat dinas. Mereka mengaku bahwa menyusun surat dinas yang baik dan benar sesuai dengan Pedoman Umum Ejaan Bahasa Indonesia sedikit sulit karena mereka hanya mengingat sebagian kecil tentang kaidah bahasa Indonesia yang dipelajari saat berada di bangku sekolah. Pada tahap ini juga, peserta kegiatan diperintah untuk menyusun surat dinas secara mandiri dengan tujuan untuk mengetahui kemampuan peserta kegiatan. Setelah dikoreksi, hasil kerja peserta kegiatan dapat dilihat dalam tabel di bawah ini.

TABEL 3

NILAI PESERTA HARI KEDUA

\begin{tabular}{|l|c|c|c|}
\hline \multirow{2}{*}{\multicolumn{1}{|c|}{ Nama }} & \multirow{2}{*}{$\begin{array}{c}\text { Pendidikan } \\
\text { Terakhir }\end{array}$} & $\begin{array}{c}\text { Struktur Surat } \\
\text { Dinas }\end{array}$ & Ejaan \\
\cline { 3 - 4 } & & - & - \\
\hline Zahar Mahmud & SMA & 95 & 80 \\
\hline Masypuk Alhamdani, S.E & S1 Ekonomi & 90 & 70 \\
\hline Faesal, A.Ma. & D2 & &
\end{tabular}


Baiq Yuliatin Ihsani, Pelatihan Penulisan Surat...

\begin{tabular}{|l|c|c|c|}
\hline \multirow{2}{*}{ Nama } & \multirow{2}{*}{$\begin{array}{c}\text { Pendidikan } \\
\text { Terakhir }\end{array}$} & $\begin{array}{c}\text { Struktur Surat } \\
\text { Dinas }\end{array}$ & Ejaan \\
\cline { 3 - 4 } & & 85 & 65 \\
\hline Rohaniyah & SMA & 90 & 70 \\
\hline Rosyhandi Permana, A.Md. & D3 & 90 & 65 \\
\hline Jaka Samudra & SMA & 90 & 65 \\
\hline Abdurrahman & SMA & 80 & 60 \\
\hline Munahar & SMP & & \\
\hline
\end{tabular}

Berdasarkan data pada tabel di atas, tampak bahwa nilai peserta kegiatan pada komponen penilaian struktur surat dinas sudah sangat baik karena peserta kegiatan hampir setiap hari melihat surat dinas yang keluar dan masuk ke Kantor Jatisela. Jadi, peserta kegiatan sudah sangat hafal dengan struktur surat dinas. Namun, yang menjadi masalah adalah penggunaan ejaan bahasa Indonesia. Pada tebel di atas tampak bahwa nilai ejaan peserta kegiatan masih kurang baik karena dilatarbelakangi oleh pendidikan terakhir peserta kegiatan. Di antara perangkat/staf desa, hanya 2 orang yang memiliki tingkat penguasaan ejaan yang baik. Oleh karena itu, tim pelaksanan kegiatan akan memfokuskan materi pada ejaan bahasa Indonesia.

c. Hari ketiga, tim pelaksana kegiatan menyampaikan hasil latihan pada hari kedua. Kemudian, tim pelaksana memberikan pemahaman teori yang lebih mendalam terkait dengan kesalahan ejaan saat pelatihan di hari kedua. Setelah penyampaian teori, peserta kegiatan melakukan latihan penyusunan surat dinas tahap II. Adapun hasil kerja peserta kegiatan penysusunan surat dinas dapat dilihat pada tabel di bawah ini.

TABEL 4

NILAI PESERTA HARI KETIGA

\begin{tabular}{|l|c|c|c|}
\hline \multirow{2}{*}{ Nama } & \multirow{2}{*}{$\begin{array}{c}\text { Pendidikan } \\
\text { Terakhir }\end{array}$} & $\begin{array}{c}\text { Struktur Surat } \\
\text { Dinas }\end{array}$ & Ejaan \\
\cline { 3 - 4 } & SMA & - & - \\
\hline Zahar Mahmud & S1 Ekonomi & 95 & 95 \\
\hline Masypuk Alhamdani, S.E & D2 & 90 & 85 \\
\hline Faesal, A.Ma. & SMA & 90 & 80 \\
\hline Rohaniyah & D3 & 95 & 85 \\
\hline Rosyhandi Permana, A.Md. & SMA & 90 & 80 \\
\hline Jaka Samudra & SMA & 90 & 75 \\
\hline Abdurrahman & SMP & 80 & 75 \\
\hline Munahar & \multicolumn{2}{|c|}{} \\
\hline
\end{tabular}

Berdasarkan tabel di atas, nilai ejaan peserta kegiatan sudah sangat baik, artinya bahwa ada peningkatan dalam memahami Ejaan Bahasa Indonesia. Pada hari ini juga, peserta kegiatan dan tim pelaksana mengadakan refleksi dan evaluasi mengenai materi yang sudah disampaikan. Dengan demikian, peserta kegiatan dapat menyusun surat dinas dengan baik dan benar sesuai Pedoman Umum Ejaan Bahasa Indonesia.

\section{Kendala Pelaksanaan Program}

Pelatihan penyusunan surat dinas yang baik dan benar sesuai dengan Pedoman Umum Ejaan Bahasa Indonesia ini dilaksanakan dalam rangkaian kegiatan pengabdian pada masyarakat. Dalam hal ini, pengabdian dilaksanakan 
di Kantor Desa Jatisela, Gunung Sari Lombok Barat. Perangkat/staf desa memiliki pekerjaan, yaitu melayani masyarakat dalam berbagai keperluan. Untuk itu, pelaksanaan program pengabdian pada masyarakat ini kurang efektif karena waktu yang sangat terbatas. Adapun kendala pelatihan ini dapat dirincikan sebagai berikut.

a. Waktu pelaksanaan terlalu singkat, hanya tiga hari sehingga hasilnya kurang maksimal.

b. Motivasi diri perangkat/staf desa terhadap kemampuan diri sendiri rendah, hal ini ditunjukkan dengan jumlah peserta dan penyediaan sarana dan prasarana.

c. Tidak pernah ada pelatihan semacam ini, sehingga kegiatan ini merupakan pengalaman baru.

d. Pemahaman materi sangatlah rendah.

e. Merasa kurang waktu untuk mempelajari materi tentang ejaan karena tugas perangkat/staf desa yang melayani masyarakat sepanjang hari dengan berbagai keperluan dan masyarakat.

f. Kurangnya buku sumber dan dukungan dari pemerintah akan pentingnya menggunakan Bahasa yang baik sesuai dengan Pedoman Umum Ejaan Bahasa Indonesia.

\section{PENUTUP}

Berdasarkan hasil kegiatan pengabdian pada masyarakat yang berupa pelatihan penyusunan surat dinas yang baik dan benar sesuai dengan Pedoman Umum Ejaan Bahasa Indonesia dapat disimpulkan hal-hal sebagai berikut.

1. Pelatihan penyusunan surat dinas yang baik dan benar sesuai dengan Pedoman Umum Ejaan Bahasa Indonesia dapat dilaksanakan dengan sukses, lancar sesuai dengan rencana.

2. Kegiatan pelatihan ini memberikan pengetahuan kepada para perangkat/staf desa tentang penyusunan surat dinas yang baik dan benar sesuai dengan Pedoman Umum Ejaan Bahasa Indonesia.

3. Tingkat pemahaman peserta kegiatan tentang penyusunan surat dinas yang baik dan benar sesuai dengan Pedoman Umum Ejaan Bahasa Indonesia meningkat setelah diadakan pelatihan ini.

4. Perangkat/staf desa mengalami beberapa kendala dalam menyusun surat dinas yang baik dan benar, di antaranya kurangnya waktu dan kesibukan perangkat/staf desa dalam melayani masyarakat untuk berbagai keperluan.

\section{DAFTAR PUSTAKA}

Afifuddin dan Beni A. S. 2009. Metode Penelitian Kualitatif. Bandung: Pustaka Setia Alwi, H. 2010. Tata Bahasa Baku Bahasa Indonesia. Jakarta: Balai Pustaka.

Arifin, Z. 1987. Penggunaan Bahasa dalam Surat Dinas. Jakarta: PT. Mediyatama Sarana Perkasa.

Dewi, R. 2013. Analisis Kesalahan Pemakaian Huruf Kapital dan Kesalahan Penulisan Kata pada Tajuk Rencana Koran Lombok Post Periode 2013. Mataram: Universitas Muhammadiyah Mataram

Keraf, G. 2004. Komposisi. Flores: Nusa Indah

Mahsun. 2011. Metode Penelitian Bahasa (Tahapan, Strategi, Metode, dan Tekniknya). Jakarta: Rajawali Pers

Moleong, L. J. 2013. Metode Penelitian Kualitatif. Bandung: Remaja Rosdakarya

Muslich, M. 2014. Tata Bentuk Bahasa Indonesia: Kajian ke arah Tatabahasa Deskriptif. Jakarta: Bumi Aksara 
Nasucha, dkk. 2012. Bahasa Indonesia untuk Penulisan Karya Tulis Ilmiah. Yogyakarta: Media Perkasa.

Sabariyanto, D. 1988. Bahasa Surat Dinas. Yogyakarta: PT. Mitra Gama Widya.

Soedjarwo. 2007. Beginilah Menggunakan Bahasa Indonesia. Yogyakarta: Gadjah Mada University Press

Sugihastuti. 2014. Bahasa Laporan Penelitian. Yogyakarta: Pustaka Pelajar Offset Suparjati. 1999. Surat-Menyurat dalam Perkantoran. Yogyakarta: Kanisius.

Sustyorini, E.N. 2013. Kesalahan Penggunaan Ejaan Surat Dinas di SDN Dinoyo Lamongan. Jember: Universitas Jember

Tim Permata Press. 2015. Pedoman Umum Ejaan Bahasa Indonesia. Jakarta: Permata Press 